\title{
Game ship control sensitivity in collision situations
}

\author{
J. Lisowski \\ Department of Ship Automation, Faculty of Electrical Engineering, \\ Gdynia Maritime University, Poland
}

\begin{abstract}
The paper introduces sensitivity of a safe ship control to inaccurate data from the ARPA anti-collision radar system and to changes of the process control parameters. Computer simulations of safe ship's trajectories are illustrated. Sensitivity characteristics of non-cooperative multistage positional game and non-cooperative multistep matrix game control algorithms on certain example of a navigational situation in the Skagerrak Strait in restricted visibility at sea are calculated.

Keywords: marine navigation, safety at sea, safe ship control, optimal control, game control.
\end{abstract}

\section{Introduction}

The process of handling a ship as a complex dynamic control object depends both on the accuracy of details concerning the current navigational situation obtained from the Automatic Radar Plotting Aids (ARPA) anti-collision system and on the form of the process model used for the control synthesis [1-3].

The ARPA system enables to track automatically at least 20 encountered $j$ ships as is shown on Figure 1, determination of their movement parameters (speed $V_{j}$, course $\psi_{j}$ ) and elements of approach to the own ship ( $D_{\min }^{j}=D C P A_{j}$ Distance of the Closest Point of Approach, $T_{\min }^{j}=T C P A_{j}$ - Time to the Closest Point of Approach) and also the assessment of the collision risk $r_{j}$ [4-6].

The functional scope of a standard ARPA system ends with the trial manoeuvre altering the course or the ship's speed selected by the navigator [7]. 


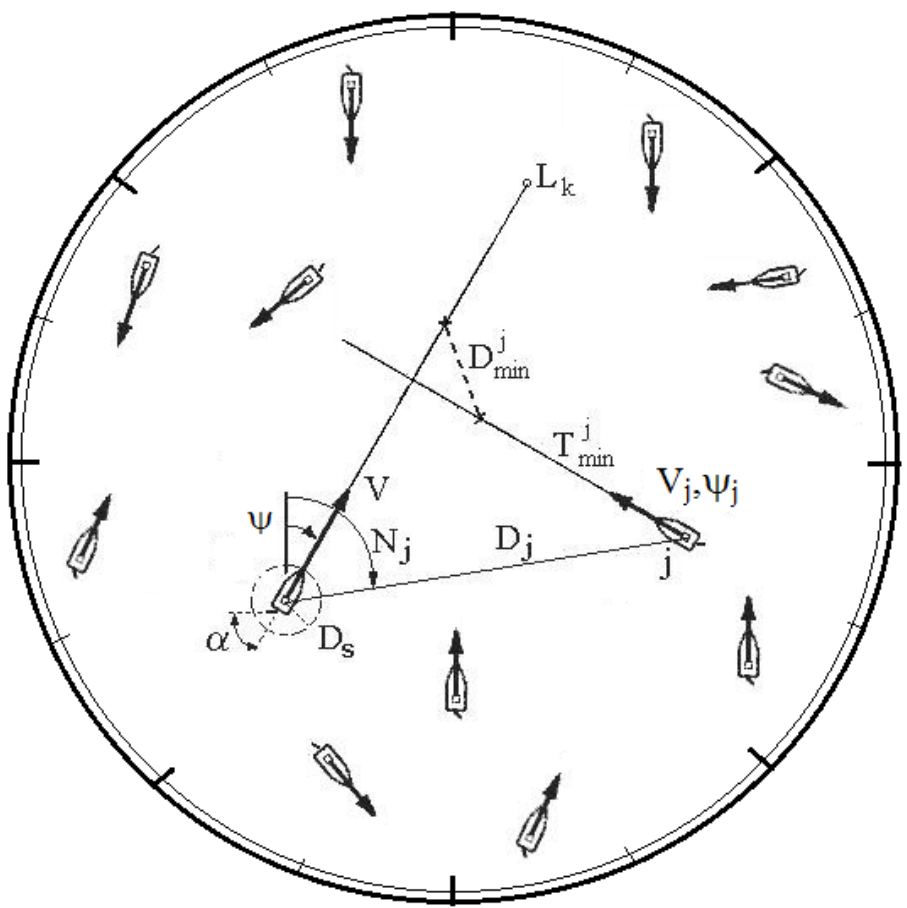

Figure 1: Navigational situation of passing of the own ship with $j$ ship encountered moving at $V_{j}$ speed and $\psi_{j}$ course.

There are various methods for the avoidance of ships collision. The simplest method is determination of the manoeuvre of a change of course or a speed of own ship in relation to the most dangerous ship encountered. Most adequate to the real character of control process is determination of a game trajectory of the ship [8-11].

\section{Sensitivity of game ship control}

The investigation of sensitivity of the game control makes, for sensitivity analysis of the game, the final payment measured as the final deviation of $d\left(t_{k}\right)=d_{k}$ of the safe game trajectory from the reference trajectory.

Taking into consideration the practical application of the game control algorithm for the own ship in a collision situation it is recommended to perform the analysis of sensitivity of a safe control with regard to the accuracy degree of the information received from the anti-collision ARPA radar system in the current approach situation, from one side and also with regard to the changes in kinematical and dynamic parameters of the control process from the other side [12-15]. 
Admissible average errors that can be contributed by sensors of anti-collision system can have following values for:

radar,

- bearing: $\pm 0,22^{\circ}$,

- form of cluster: $\pm 0,05^{\circ}$,

- form of impulse: $\pm 20 \mathrm{~m}$,

- margin of antenna drive: $\pm 0,5^{\circ}$,

- $\quad$ sampling of bearing: $\pm 0,01^{\circ}$,

- sampling of distance: $\pm 0,01 \mathrm{~nm}$,

gyrocompas: $\pm 0,5^{\circ}$,

log: $\pm 0,5 \mathrm{kn}$,

$>$ GPS: $\pm 15 \mathrm{~m}$.

The algebraic sum of all errors, influent on picturing of the navigational situation, cannot exceed $\pm 5 \%$ or $\pm 3^{\circ}$.

\subsection{Sensitivity of the safe ship control to inaccuracy of information from ARPA system}

Let $I_{j}$ represent such a set of state process control information on the navigational situation that:

$$
I_{j}=\left\{V, \psi, V_{j}, \psi_{j}, D_{j}, N_{j}\right\}
$$

Let then $I_{j}^{e}$ represent a set of information from ARPA system containing errors of measurement and processing parameters:

$$
I_{j}^{e}=\left\{I_{j} \pm \delta I_{j}\right\}=\left\{V \pm \delta V, \psi \pm \delta \psi, V_{j} \pm \delta V_{j}, \psi_{j} \pm \delta \psi_{j}, D_{j} \pm \delta D_{j}, N_{j} \pm \delta N_{j}\right\}
$$

Relative measure of sensitivity of the final payment in the game $s_{i}$ as a final deviation of the ship's safe trajectory $d_{k}$ from the reference trajectory will be:

$$
\begin{gathered}
s_{i}=\left(I_{j}^{e}, I_{j}\right)=\left|\frac{d_{k}^{e}\left(I_{j}^{e}\right)-d_{k}\left(I_{j}\right)}{d_{k}\left(I_{j}\right)}\right| 100 \% \\
s_{i}=\left\{s^{V}, s^{\psi}, s^{V_{j}}, s^{\psi_{j}}, s^{D_{j}}, s^{N_{j}}\right\}
\end{gathered}
$$

\subsection{Sensitivity of the safe ship control to process parameters alterations}

Let $P$ represent a set of parameters of the state process control:

$$
P=\left\{t_{m}, D_{s}, \Delta t_{k}, \Delta V\right\}
$$

Let then $P^{e}$ represent a set of parameters containing errors of measurement and processing parameters: 


$$
P^{e}=\{P \pm \delta P\}=\left\{t_{m} \pm \delta t_{m}, D_{s} \pm \delta D_{s}, t_{k} \pm \delta_{k}, \Delta V \pm \delta \Delta V\right\}
$$

Relative measure of sensitivity of the final payment in the game $s_{p}$ as a final deflection of the ship's safe trajectory $d_{k}$ from the assumed trajectory will be:

$$
\begin{gathered}
s_{p}=\left(P^{e}, P\right)=\left|\frac{d_{k}^{e}\left(P^{e}\right)-d_{k}(P)}{d_{k}(P)}\right| 100 \% \\
s_{p}=\left\{s^{t_{m}}, s^{D_{s}}, s^{\Delta t_{k}}, s^{\Delta V}\right\}
\end{gathered}
$$

where:

$t_{m}$ - advance time of the manoeuvre with respect to the dynamic properties of the own ship,

$t_{k}$ - duration of one stage of the ship's trajectory,

$D_{s}$ - safe distance,

$\Delta V$ - reduction of the own ship's speed for a deflection from the course greater than $30^{\circ}[16]$.

\section{Computer support algorithms}

In practice, methods of selecting a manoeuvre assume a form of approximate control algorithms supporting navigator's decision in a collision situation.

\subsection{Non-cooperative multi-stage positional game ncmpg algorithm}

The optimal control of the own ship $u_{0}^{*}(t)$, equivalent for the current position $p(t)$ to the optimal positional steering $u_{0}^{*}(p)$, is determined from the condition:

$$
J^{*}=\min _{u_{0}}\left\{\max _{u_{j}} \min _{u_{0}^{j}} \int_{t_{0}}^{t_{k}} V(t) d t\right\}=D^{*}\left(t_{0}, t_{k}\right)
$$

$D^{*}$ refers to the continuous function of the manoeuvring goal of the own ship, characterising the distance of the ship at the initial moment $t_{0}$ to the nearest turning point $L_{k}$ on the reference $p_{r}\left(t_{k}\right)$ route of the voyage.

Using the function of $l p$ - linear programming from the Optimisation Toolbox MATLAB, the positional multi-stage game non-cooperative manoeuvring ncmpg program has been designed for the determination of the own ship's safe trajectory in a collision situation [17-19].

\subsection{Non-cooperative multi-step matrix game ncmmg algorithm}

The dynamic game is reduced to a multi-step matrix game of a $j$ number of participants. The matrix game $\boldsymbol{R}=\left[r_{j}\left(u_{j}, u_{0}\right)\right]$ includes the values determined 
previously on the basis of data taken from an anti-collision system ARPA the value a collision risk $r_{j}$ with regard to the determined strategies $u_{0}$ of the own ship and those $u_{j}$ of the $j$-th encountered objects.

The matrix risk contains the same number of columns as the number of own ship strategies and the number of lines which correspond to a joint number of $j$ met ships strategies.

The value of the risk of the collision $r_{j}$ is defined as the reference of the current situation of the approach described by the parameters $D_{\min }^{j}$ and $T_{\operatorname{mir}}^{j}$, to the assumed assessment of the situation defined as safe and determined by the safe distance of approach $D_{s}$ and the safe time $T_{s}$ - which are necessary to execute a manoeuvre avoiding a collision with consideration actual distance $D_{j}$ between own ship and encountered $j$-th ship:

$$
r_{j}=\left[w_{1}\left(\frac{D_{\min }^{j}}{D_{s}}\right)^{2}+w_{2}\left(\frac{T_{\min }^{j}}{T_{s}}\right)^{2}+\left(\frac{D_{j}}{D_{s}}\right)^{2}\right]^{-\frac{1}{2}}
$$

where the weight coefficients $\left(w_{l}, w_{2}\right)$ are dependent on the state visibility at sea, dynamic length and dynamic beam of the ship, kind of water region.

The constraints affecting the choice of strategies $\left(u_{0}, u_{j}\right)$ are a result of International Collision Regulations (COLREG).

The problem of determining an optimal strategy may be reduced to the task of solving dual linear programming problem. Mixed strategy components express the distribution of probability $p_{j}\left(u_{j}, u_{0}\right)$ of using pure strategies by the players.

As a result of using the following form for the control goal:

$$
J^{*}=\min _{u_{0}} \max _{u_{j}} r_{j}
$$

the probability matrix $\boldsymbol{P}=\left[p_{j}\left(u_{j}, \boldsymbol{u}_{0}\right)\right]$ of using particular pure strategies may be obtained.

Using the function of $l p$ - linear programming from the Optimisation Toolbox MATLAB, the matrix multi-step game manoeuvring $n \mathrm{cmmg}$ program has been designed for the determination of the own ship's safe trajectory in a collision situation [20, 21].

\section{The calculation of sensitivity characteristics}

\subsection{Computer simulation of safe ship's trajectories}

Computer simulation of ncmpg and ncmmg algorithms, as a computer software supporting the navigator manoeuvring decision, were carried out on an example of a real navigational situation of passing $\mathrm{j}=17$ encountered ships in restricted visibility when $D_{s}=1 \mathrm{~nm}$ (nautical mile). The situations were registered in the 
Skagerrak Strait on board $r / v$ HORYZONT II, a research and training vessel of the Gdynia Maritime University, on the radar screen of the ARPA anti-collision system Raytheon (Figs 2 and 3).

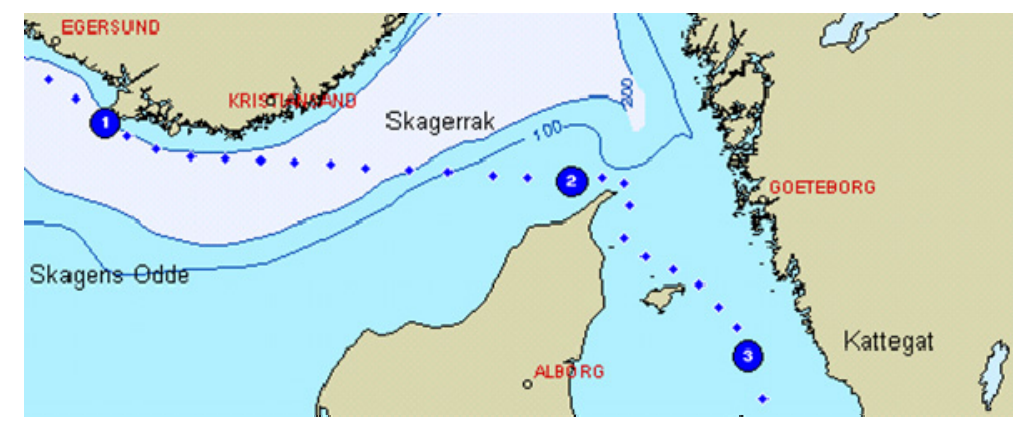

Figure 2: The place of identification of navigational situations in the Skagerrak Strait.

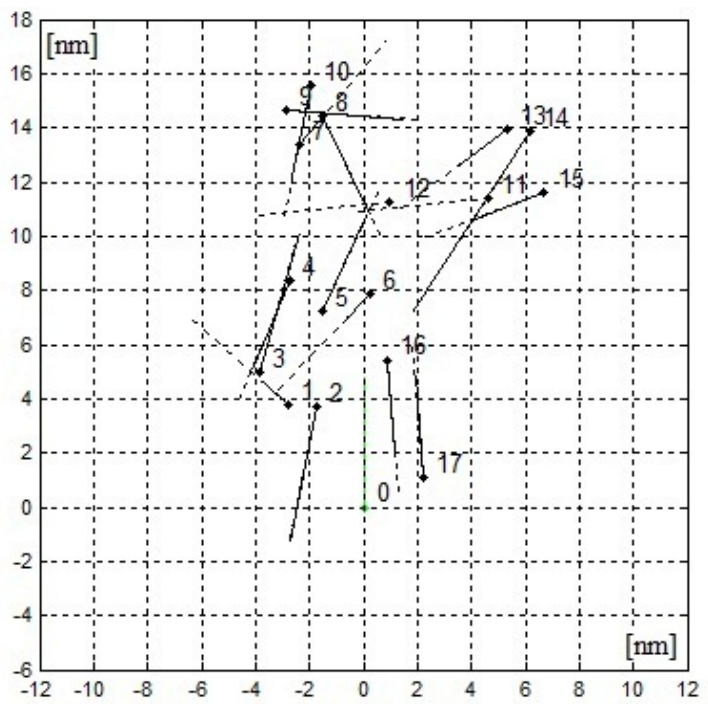

Figure 3: The 12 minute speed vectors of the own ship and 17 encountered ships in a situation occurring in the Skagerrak Strait. 


\subsection{Sensitivity characteristics of ncmpg algorithm}

Computer simulation of ncmpg algorithm was carried out in Matlab/Simulink software (Fig. 4). In addition, sensitivity characteristics (Fig. 5) for the changes of the values were determined:

$$
\Delta I_{j}=\frac{\delta I_{j}}{I_{j}}, \quad \Delta P=\frac{\delta P}{P}
$$

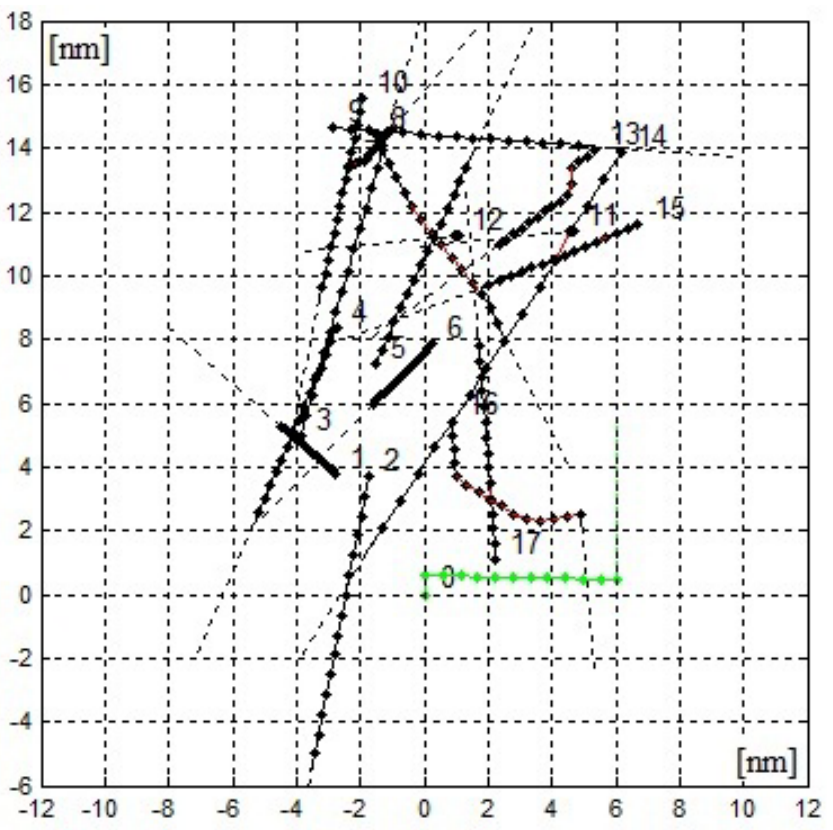

Figure 4: $\quad$ Safe trajectory of the own ship for $n c m p g$ algorithm, $d\left(t_{k}\right)=6.06 \mathrm{~nm}$.

\subsection{Sensitivity characteristics of ncmmg algorithm}

Computer simulation of ncmmg algorithm was carried out in Matlab/Simulink software (Fig. 6). In addition, sensitivity characteristics for changes of the values $\Delta \mathrm{I}_{\mathrm{j}}$ and $\Delta \mathrm{P}$ were determined (Fig. 7). 

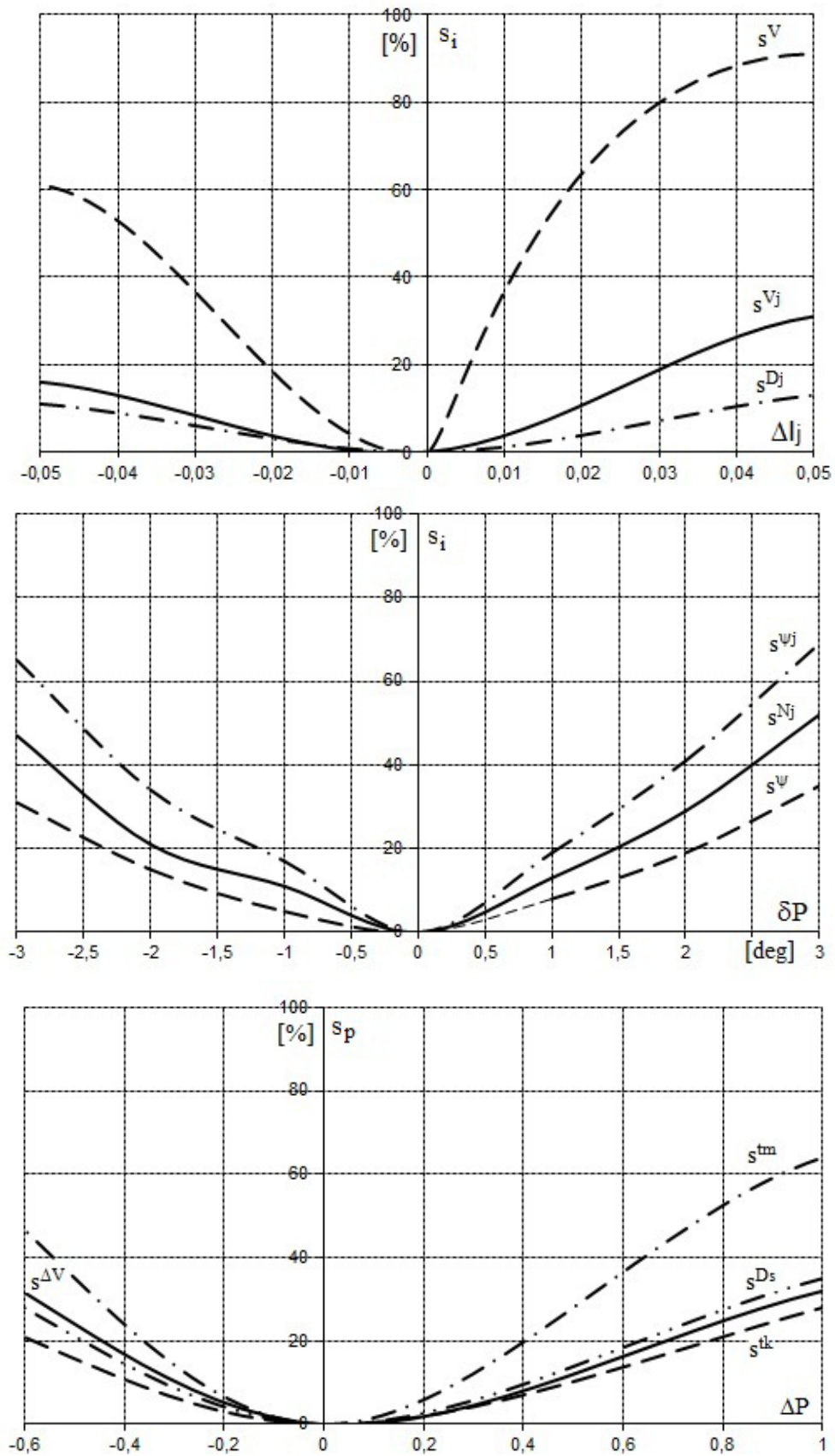

Figure 5: Sensitivity characteristics of the safe ship control according to ncmpg algorithm. 


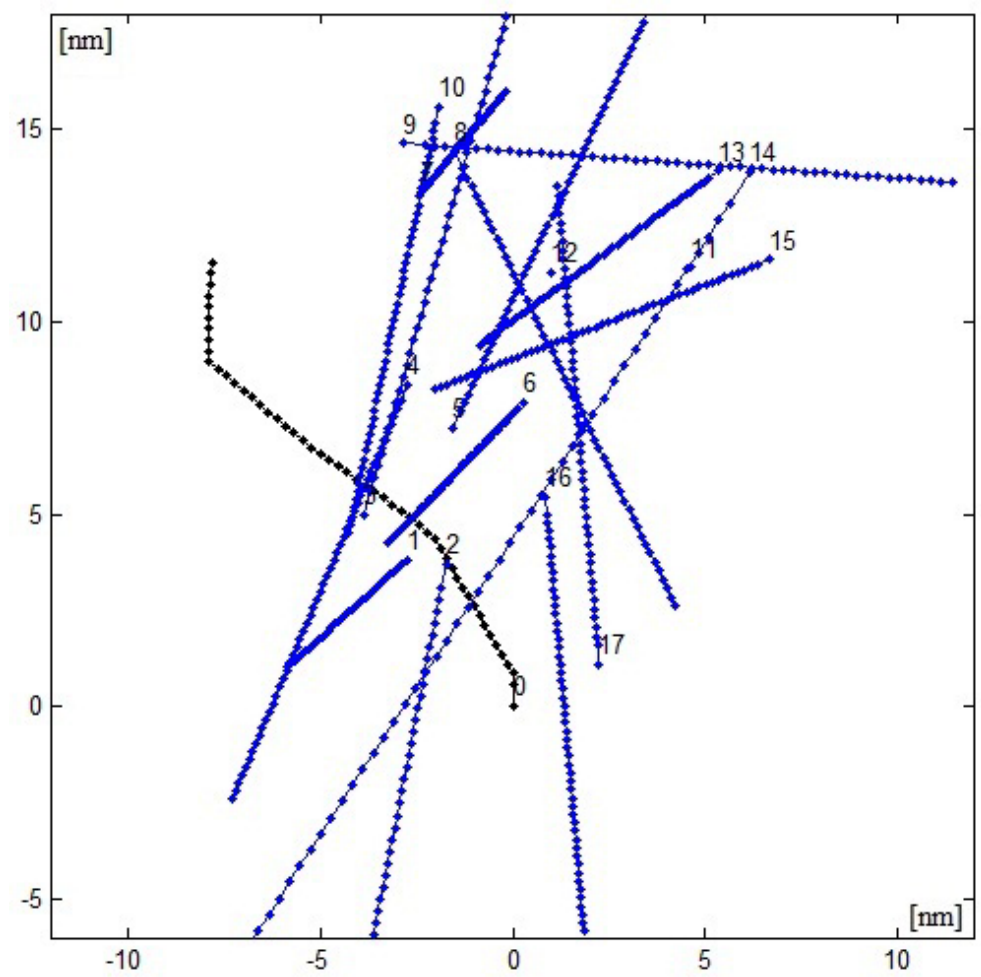

Figure 6: Safe trajectory of the own ship for ncmmg algorithm, $d\left(t_{k}\right)=7.59 \mathrm{~nm}$.

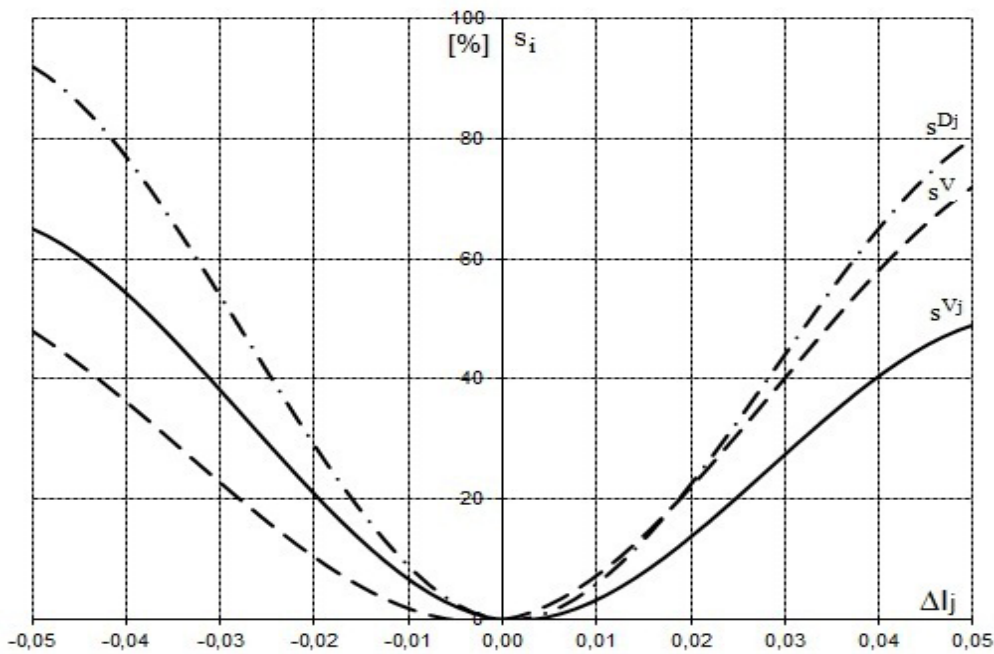

Figure 7: Sensitivity characteristics of the safe ship control according to ncmmg algorithm. 

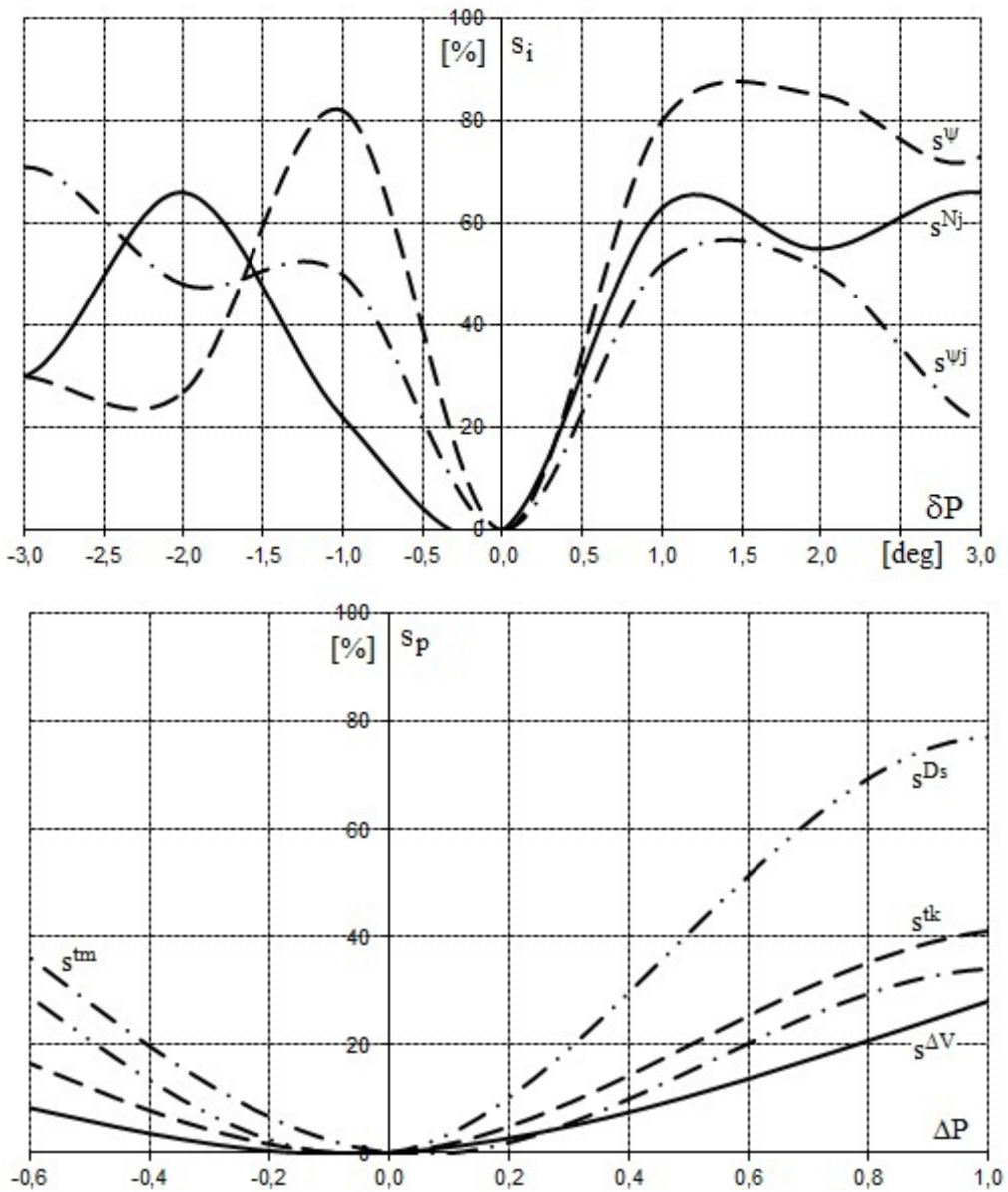

Figure 7: Continued.

\section{Conclusion}

Application of simplified models of the dynamic game of process to synthesis of the optimal control allows the determination of the own ship safe trajectory in a situations of passing a greater number of encountered ships as a certain sequence of the course and the speed manoeuvres.

Developed algorithms also take into consideration the COLREGS Rules and the advance time of the manoeuvre approximating ship's dynamic properties and evaluates the final deviation of the real trajectory from reference value.

Sensitivity of the final game payment:

$>$ is the least for changes of the duration of one stage trajectory and for changes of the advance time manoeuvre, 
is the greatest for changes of the own and met ships speeds and courses,

$>$ grows with the degree of the ships cooperation for the purpose of avoiding of collision,

$>$ grows with the number of meeting ships and with the quantity of admissible strategies for own ship and passing ships.

The considered control algorithms are, in a certain sense, formal models of the thinking process of a navigator steering the ship's movement and making up manoeuvring decisions.

Therefore they may be applied in the construction of a new model of ARPA system containing a computer supporting the navigator's decision making.

\section{References}

[1] Bist, D.S., Safety and security at sea, Butterworth Heinemann: Oxford New Delhi, 2000.

[2] Cahill, R.A., Collisions and their causes, The Nautical Institute: London, 2002.

[3] Nise, N.S., Control systems engineering, John Wiley and Sons: New York, 2011.

[4] Cockcroft, A.N. and Lameijer, N.F., Collision avoidance rules, Elsevier: Amsterdam - Tokyo, 2006.

[5] Gluver, H. and Olsen, D., Ship collision analysis, Balkema: Rotterdam, 1998.

[6] Modarres, M., Risk analysis in engineering, Taylor and Francis Group: Boca Raton, 2006.

[7] Bole, A., Dineley, B. and Wall, A., Radar and ARPA manual, Elsevier: Amsterdam-Tokyo, 2006.

[8] Lisowski, J., Optimization decision support system for safe ship control, in C.A. Brebbia (Ed), Risk Analysis, WIT Press: Southampton-Boston, pp. 259-272, 2010.

[9] Pietrzykowski, Z., The navigational decision support system on a sea-going vessel, Maritime University: Szczecin, 2011.

[10] Straffin, P.D., Game theory and strategy, Scholar: Warszawa, 2001 (in polish).

[11] Szlapczynski, R. and Smierzchalski, R., Supporting navigators' decisions by visualizing ship collision risk. Polish Maritime Research, 1(59), pp. 8388, 2009.

[12] Baba, N. and Jain, L.C., Computational intelligence in games, PhysicaVerlag: New York, 2001.

[13] Isaacs, R., Differential games, John Wiley and Sons, New York, 1965.

[14] Lisowski, J., Sensitivity of safe game ship control on base information from ARPA radar, in G. Kouemou (Ed), Radar Technology, In-The: Vukovar, pp. 61-86, 2009.

[15] Lisowski, J., The sensitivity of safe ship control in restricted visibility at sea, in A. Weintrit (Ed), Marine navigation and safety of sea 
transportation, Gdynia Maritime University and The Nautical Institute in London: Gdynia, pp. 75-84, 2011.

[16] Zio, E., Computational methods for reliability and risk analysis. Series on Quality, Reliability and Engineering Statistics, 14, Word Scientific: New Jersey-Chennai, pp. 295-334, 2009.

[17] Engwerda, J.C., LQ Dynamic Optimization and Differential Games, John Wiley and Sons: West Sussex, 2005.

[18] Lisowski J., The multistage positional game of marine objects with different degree of cooperation. Solid State Phenomena. 180, Trans Tech Publications: Switzerland, pp. 56-63, 2012.

[19] Millington, I. and Funge, J., Artificial intelligence for games, Elsevier: Amsterdam-Tokyo, 2009.

[20] Nisan, N., Roughgarden, T., Tardos, E. and Vazirani, V.V., Algorithmic Game Theory, Cambridge University Press: New York, pp. 717-733, 2007.

[21] Osborne, M.J, An Introduction to Game Theory, Oxford University Press: New York, 2004. 